\title{
Is Dhaka Stock Exchange (DSE) Efficient? A Comparison of Efficiency Before and After the Market Crisis of 2010
}

\author{
Maruf Rahman Maxim¹, Tasfia Awal Miti², S.M Arifuzzaman ${ }^{3}$ \\ ${ }^{1}$ Post Graduate Research Studies, University of Western Sydney, Sydney, Australia \\ ${ }^{2}$ South Asia Region Financial Management, World Bank, Dhaka, Bangladesh \\ ${ }^{3}$ Senior lecturer, Department of Business Administration, East West University, Bangladesh
}

\begin{abstract}
This paper tests for the weak form of efficiency in DSE. A major objective of this paper is to compare and analyse the efficiency of the market before and after the market crash of December, 2010. The sample includes DSEGEN price index daily closing values. The data is divided among two time periods, year 2009-2010 is used to test the efficiency before the market crash and 2011-2012 is used to test the efficiency after the market crash. Kolmogorov-Smirnov and the Shaprio-Wilk tests are used to test the normality of returns and for both the time periods, the returns distributions are non normal. Runs test is used to test for the randomness of returns. The result of runs test is quite interesting. It shows that returns were not random before the market crash. Numerous other previous researches also show non randomness of returns in DSE. But surprisingly random walk is observed for the returns after the market crash. It requires further studies to understand such abnormality.
\end{abstract}

Keywords: Efficient Market Hypothesis; DSE; Random Walk Model; Weak Form of Efficiency. JEL Classification Code: L11, H12

\section{INTRODUCTION}

A ccording to the efficient market hypothesis no investor can employ any investment strategy to consistently beat the market. In other words at any given time the market price of a stock reflects all available information and hence is the true value of it. Stock prices adjust swiftly with the arrival of new information and leave no opportunity for investors to capitalize on the news [1]. Weak form of efficiency (WFEMH) suggests that past series of share prices cannot be used to foresee the future prices. It is widely believed that emerging markets experience this least form of efficiency and numerous researches have been conducted on testing the WFEMH in emerging markets. Some of these studies are discussed in the literature review section of this paper. This paper will test for WFEMH in Dhaka stock exchange. The result of the test will determine whether DSE shows the least form of efficiency and whether it's possible to beat the market pursuing any particular investment strategy. One of the major significance of this research is that it tries to understand and compare the market efficiency of DSE before and after the stock market crash of December 2010.

December 2010, Bangladesh stock market crash

The journey of Bangladesh stock market started from 28 April, 1954 when the East Pakistan Stock Exchange Association Ltd. was established. At the early stage there were very few enlisted companies. During 1976, there were only 9 listed companies with total paid up capital of Tk.0 .138 billion and market capitalization of Tk. 0.147 billion which was 0.138 percent of GDP [2].
The stock market of the country was growing at a slow pace at first but there was a large surge in the stock market in the summer and fall of 1996. According to Mollik and Bepari [2] DSE general index grew from 832 in January 1, 1996 to 3567 in November 14. The market eventually crashed in December of 1996 and the index started to decline significantly since then, with the index of DSE assuming a value of 507.33 as of November of 1999 , resulting in a cumulative decline of 83.44 percent from 1996 to 1999 with the annual rate of 27.82 percent. This was the first major crash in the history of Bangladesh stock market. The second one took place very recently. The problem was initiated in 2009 and the market was unstable throughout that year. By the end of 2010 it was evident that the market was overheated. The central bank took a step and wanted to slow things down by controlling liquidity. The mayhem started on December of 2010. On December $13^{\text {th }}$ the DSE general index (DSEGEN) dropped by 285 points. The second fall was on December $19^{\text {th }}$ which struck even harder. The DSEGEN fell by 551 points in a single day. That was the largest fall in the 55 year history of Dhaka stock exchange [3]. The market stood at 5500 points on October 2010 compared to 8900 points on the previous year.

\section{Literature ReVIeW}

Random walk model (RWM) has been used very frequently over the years to test the market efficiency in both developed and developing markets. Some of the 
Asian Business Review, Volume 3, Number 2/2013 (Issue 6)

ISSN 2304-2613 (Print); ISSN 2305-8730 (Online)

notable works would include Fama [1]; and Fama [4]. The random walk model says successive price changes are independent and identically distributed random variables. It implies that future price changes cannot be predicted based on the historic price. A major problem for emerging markets is that they are very thinly traded and so are vulnerable to manipulation. The literature on RWM and efficiency is widely divided among two major schools when it comes to emerging markets. One school advocates for RWM and WFEMH and their empirical evidence in emerging markets. See Paul [5]; Chan and Gup et al. [6]; Dickinson and Muragu [7]; Ojah and Karemera [8] ; Claire and Gilmore al.[9]; Verma[10]; Asiri [11]. Where as the other group argues against it. See Chaudhuri[12]; Mobarek and Keasey [13]; Liu [14]; Ntim and Danbolt et al. [15]; Mishra [16].

Numerous researches have been conducted in the context of Bangladesh testing for weak form of efficiency. Alam [17] found that DSE follows a random walk testing data of 1986-1995. Mobarek [15] tested the price index between (1988-1997) and concluded it does not follow a random walk. Hasan [18] and Rahman [19] found the same thing as Mobarek [15] and concluded that market does not follow a random walk. However none of the studies compared the efficiency of two different time periods. Comparison is required to understand the trend of efficiency and the underlying reasons behind it. This understanding can result in better policy making. Moreover not much work has been done concentrating the post 2010 market crisis. This research will contribute in covering such gaps in the literature.

When it comes to the methods used for testing WFEMH the two methods used profoundly are filter test and statistical tests of independence between rates of return such as autocorrelation tests and runs tests [20]. Filter test is used to figure out whether filter rule holds or not. Filter rule is a trading strategy where the investor makes a rule on when to buy and sell based on price changes from historic lows and highs. The second type of test is used to determine the randomness of the rates of return [21].

\section{Data and Methodology}

All tables and figures will be processed as images. You need to embed the images in the paper itself. Please don't send the images as separate files.

\subsection{Data}

This research is aiming to test the market efficiency of two different periods and so the data is divided among two parts. The first part of this research will look at the efficiency of DSE before the market crash of 2010. For this part the data used is from January $1^{\text {st }} 2009-31^{\text {st }}$ December 2010. The second part of the research focuses on the post crash efficiency of DSE and the data used here is from January $1^{\text {st }} 2011-31^{\text {st }}$ December 2012.
Instead of using every individual stock enlisted in DSE we used the DSE General index. The data used are daily closing values for the above mentioned periods.

\subsection{Hypotheses}

The intention of this study is to do a comparative analysis of DSE's efficiency before and after the market crash of 2010. The null hypotheses for both these periods (before and after 2010) state that market movements are random and they are not predictable. If the null hypothesis holds then it proves weak form of efficiency in DSE. But before testing the randomness of returns it tests the nature of their distribution. Understanding the distribution is required to decide what type of statistical tool should be used to test randomness. Certain statistical tests (such as the autocorrelation test) assume normality of distribution. Using such tests when the distribution is not normal can give faulty results [22].

The hypotheses are listed below:

First: (Before the market crash of 2010)

$H_{0}$ : The DSE general index returns follow a normal distribution.

$H_{1}$ : The DSE general index returns do not follow a normal distribution.

Second: (Before the market crash of 2010)

$H_{0}$ : The DSEGEN returns are random over the time period of the study.

$H_{1}$ : The DSEGEN returns are not random over the time period of the study.

Third: (After the market crash of 2010)

$H_{0}$ : The DSE general index returns follow a normal distribution.

$H_{1}$ : The DSE general index returns do not follow a normal distribution.

Fourth: (After the market crash of 2010)

$H_{0}$ : The DSEGEN returns are random over the time period of the study.

$H_{1}$ : The DSEGEN returns are not random over the time period of the study.

\subsection{Statistical methods}

As discussed in the literature review section, autocorrelation test and runs test are the most popular statistical tools when it comes to testing the randomness of the returns. This research uses the autocorrelation test when the distribution of returns is normal. When the distribution is not normal the research uses the runs test. The autocorrelation test or serial correlation test is used to test the relationship between time series and its own values over different time lags. If the autocorrelation is negative it implies that it is mean reversal and accepts 
the null hypothesis. A significant positive autocorrelation means there is a trend in the series. A truly random data series will have a zero serial correlation coefficient. The beta coefficient from the following regression equation measures the serial correlation of stock $i$ with a lag of $k$ periods:

$$
\mathrm{r}_{\mathrm{i}, \mathrm{t}}=\propto_{\mathrm{i}}+\mathrm{B}_{\mathrm{i}} \mathrm{r}_{\mathrm{i}, \mathrm{t}-\mathrm{k}}+\varepsilon_{\mathrm{i}, \mathrm{t}}(1)
$$

Where $r_{i, t}$ represents the return of stock $i$ at time $t, \propto_{i}$ and $B_{i}$ are constants, $\varepsilon_{\mathrm{i}, \mathrm{t}}$ represents random error, and $\mathrm{k}$ represents different time lags. The serial correlation tests assume normal distribution of returns. The runs test is a nonparmetic test of randomness in a series. It does not require the normal distribution of returns. A run is defined as price change sequence of the same sign, e.g.,--0+++ would constitute three runs where '- -'represents a price decrease, 0 represents no change, and " +++ " represents a price increase. For more on runs test see Moustafa [20].

The principle behind this test is that too few or too many runs, as compared with the number of runs expected in a random series, indicate non-randomness. If there are too few runs, it would mean that the stock returns in the time series do not change signs frequently, thus indicating a positive serial correlation and in turn, may imply that the price changes do not follow a random walk model. Similarly, if there are too many runs, they may suggest negative autocorrelation [23].

\section{EMPIRICAL RESULTS}

We calculated the returns using the following simple formula $\mathrm{R}=\left(\mathrm{P}_{\mathrm{t}}-\mathrm{P}_{\mathrm{t}-1}\right) / \mathrm{P}_{\mathrm{t}-1}$

Where $\mathrm{R}$ is the return of DSEGEN index, $\mathrm{P}_{t}$ is the value of the index on day $t$ and $P_{t-1}$ is the value of the index a day before $P_{t}$ The second step was testing the normality of the returns. For that we used the Kolmogorov-Smirnov test and the Shaprio-Wilk test. The normality of the returns was observed to determine what statistical method to be used between serial correlation and runs test. Both Kolmogorov-Smirnov and the Shaprio-Wilk tests show that returns of DSEGEN index do not follow a normal distribution pattern before and after the market crash of 2010. So we reject the null hypothesis of normalcy for both time periods. Autocorrelation test could not be used due to the non existence of normality in the dataset. Runs test is used to test the randomness of returns.

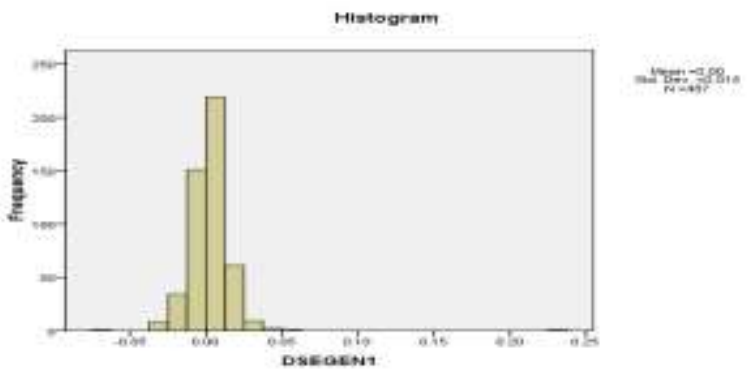

DSEGEN1-Index returns of 2009-1010

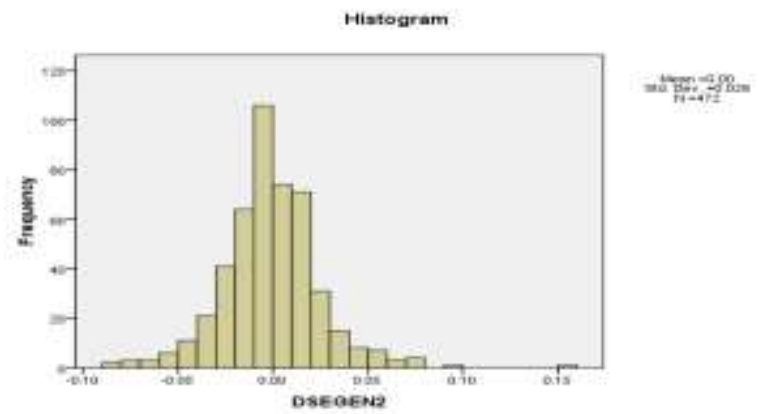

DSEGEN2-Index returns of 2011-2012

The result of the runs test is quite interesting. It reveals that at the five percent level, Z-value is -3.039 which is beyond $( \pm 1.96)$ of DSEGEN for the returns of 2009-2010, indicating non randomness. But surprisingly it shows randomness during the post collapse period. The $\mathrm{Z}$ score for DSEGEN index during the post collapse period is 1.567. For both pre and post crisis, $\mathrm{Z}$ score is negative indicating fewer actual runs than expected.

The results exhibit that DSE was not following the random walk model during the pre crisis bullish period. The market was overheated during that time but was not showing any form of efficiency. So the null hypothesis that the index returns in DSE stock market are random is rejected. On the other hand DSE showed signs of WFEMH and followed the random walk model during 2011-2012, after the crisis took place. So the null hypothesis for randomness for this time period of the study is accepted.

The result of the study suggests that following any particular trading strategy could not result in higher than market return during the post crisis period.

\section{CONCLUSION}

The finding of the research is very fascinating and gives scope for further studies. Numerous studies in the past show non existence of WFEMH in the DSE and our result is on the same line with the previous studies. But surprisingly based on the DSEGEN index data, DSE has shown significant level of WFEMH during this post crisis period. The market capitalization of DSE dropped significantly in 2011-2012 after the 2010 crisis. Investor confidence dropped drastically and most institutions and individual investors left the market or minimized their investment. Thinly traded markets are usually more prone to inefficiency but in this case our finding contradicts with it. The results of the research should be interpreted very cautiously. A lower degree of efficiency in less developed markets might be due to common characteristics of loose disclosure requirements, thinness and discontinuity in trading [24]. Further researches need to be conducted to find out the underlying reason for such abnormality. 


\section{REFERENCES}

[1] Fama. E, "Efficient Capital Markets : A Review of Theoty and Empirical Work," Journal of Finance, vol.25, pp. $383-417,1970$.

[2] A. Mollik, and M. Bepari, "Weak- Form Market Efficiency of Dhaka Stock Exchange (DSE), Bangladesh," Social science research network, Available at: http:/ / papers.ssrn.com/sol3/papers.cfm?abstract_id=1 460536, 2009.

[3] E. Bhuiyan, "Reconstructing the market," The financial express, pp. 4, December. 2011.

[4] E. Fama, "Efficient Capital Markets: II," Journal of Finance, vol.46, pp. 1575 - 1617, 1991.

[5] B. Paul, "Thin trading and stock market efficiency: A case of the Kuala Lumpur Stock Exchange," Journal of Business Finance E Accounting, vol.13, no.4, pp. 609-617. 1986.

[6] K. Chan, B. Gup, and M. Pan, "An Empirical Analysis of Stock Prices in Major Asian Markets and the United State," The Financial Review, vol.27,pp. 289-307.1992.

[7] J.P. Dickson, K. Maragu, "Market Efficiency in Developing Countries: A Case Study of the Nairobi Stock Exchange," Journal of Business Finance $\mathcal{E}$ Accounting, vol.21,no. 1, pp. 133-150.1994.

[8] K.Ojah, and D. Karemera, "Random walks and market efficiency tests of Latin American emerging equity markets," The Financial Review, vol. 34, no. 1, pp. 57-72. 1999.

[9] G. Claire, Gilmore, and M.Ginette, "Random-Walk and Efficiency Tests of Central European Equity Markets," European Financial Management Association Conference, 2001.

[10] A.Verma, "The study of the weak form informational efficiency in Bombay Stock Market," Finance India, vol.19,no.4, pp. 1421.2005.

[11] B. Asiri, "Testing weak-form efficiency in the Bahrain stock market," International Journal of Emerging Markets, vol.3,no.1, pp. 38-53.2008.

[12] S. Choudhuri, "Short-run Share Price Behaviour: New Evidence on Weak Form of Market Efficiency," vol.16,no.4, pp. 17-21. Available at:

http:/ / www.vikalpa.com/pdf/articles/1991/1991_oct _dec_17_21.pdf,1991.

[13] A. Mobarek, and K. Keasey, Untitled paper, proc.Weakform market efficiency of an emerging Market: Evidence from Dhaka Stock Market of Bangladesh, May,2000.

[14] B.Liu, "Weak-form Market Efficiency of Shanghai Stock Exchange: An Empirical Study," available at http://www.sk.tsukuba.ac.jp/SSE/degree/h14/015361 .pdf,2003

[15] C.Ntim, J.Danbolt, and K.Opong, "An Empirical ReExamination of the Weak Form Efficient Markets Hypothesis of the Ghana Stock Market Using VarianceRatios Tests," African Finance Journal, vol.9,no.2.2007.

[16] P. Mishra, "Indian Capital Market - Revisiting Market Efficiency," Indian Journal of Capital Markets, vol.2,no.5, Available at: http://papers.ssrn.com/sol3/papers.cfm?abstract_id=1
$339901,2010$.

[17] M.I. Alam, T. Hassan, and P.Kadapakkam, "An application of variance ratio test to five asian stock markets," Review of pacific basin financial markets and policies, vol.2,pp.301-315.1999.

[18] M. Hassan, Kabir, and M. Anisul, "Market efficiency, Time varying volatility and equity returns in Bangladesh stock market,"2000.

[19] S. Rahman, F. Hossain, "Weak form efficiency: testimony of Dhaka stock exchange,"Journal of business research, vol. 8,pp.1-12. 2006.

[20] M. Moustafa, "Testing the Weak-Form Efficiency of the United Arab Emirates Stock Market," International journal of business, vol.9,no.3, pp. 316-317. 2004.

[21] F. Reilly, and K. Brown, Investment Analysis and Portfolio Management. Mason, Ohio: South-Western, Thomson, 2003.

[22] J. Urrutia, "Tests of Random Walk and Market Efficiency for Latin American Emerging Equity Markets," The Journal of Financial Research, vol.3, pp. 299 - 309.1995.

[23] D. Gujarati, Basic econometrics. Singapore: McGrawHill.1995.

[24] Errunza, R. Vihang, and L. Etienne, "The behavior of stock prices on LDC markets,"Journal of Banking and Finance, vol. 9, pp. 561-575.1985.

\section{Appendix A}

\begin{tabular}{|l|r|r|r|r|r|r|}
\hline \multicolumn{1}{|c|}{ Tests of Normality } \\
& \multicolumn{3}{|c|}{ Kolmogorov-Smirnov } & \multicolumn{3}{|c|}{ Shapiro-Wilk } \\
\cline { 2 - 7 } & Statistic & df & Sig. & Statistic & df & Sig. \\
\hline DSEGEN2 & .066 & 472 & .000 & .955 & 472 & .000 \\
DSEGEN1 & .115 & 472 & .000 & .655 & 472 & .000 \\
\hline
\end{tabular}

a. Lilliefors Significance Correction

b. DSEGEN1 is the index returns of 2009-2010 and DSEGEN2 is the index returns of 2011-2012

Appendix B

\begin{tabular}{|l|r|r|}
\hline \multicolumn{2}{|c|}{ Runs Test } \\
\hline Test Value $^{\mathrm{a}}$ & DSEGEN1 & DSEGEN2 \\
Cases < Test Value & .00 & .00 \\
Cases > = Test Value & 243 & 236 \\
Total Cases & 244 & 236 \\
Number of Runs & 487 & 472 \\
Z & 211 & 220 \\
Asymp. Sig. (2-tailed) & -3.039 & -1.567 \\
\hline
\end{tabular}

a. Median 